\title{
Ethics and the GMC core curriculum: a survey of resources in UK medical schools
}

\author{
K W M Fulford, Anne Yates and Tony Hope Oxford Practice Skills Project, University of Oxford
}

\section{Abstract}

Objectives - To study the resources available and resources needed for ethics teaching to medical students in $U K$ medical schools as required by the new GMC core curriculum.

Design - $A$ structured questionnaire was piloted and then circulated to deans of medical schools.

Setting - All UK medical schools

Results - Eighteen out of 28 schools completed the questionnaire, the remainder either indicating that their arrangements were "under review" (4) or not responding (6). Among those responding : 1) library resources, including video and information technology were found to be fairly well developed; 2) many schools had a good supply of handouts and sample cases for teaching; 3) most had a written syllabus, and 4) two-thirds examined in the subject. However, many schools indicated that there was an urgent need for: 1) full-time teachers (most ethics teaching is still by part-time and voluntary staff); funding for books and journals, and 3) additional teaching materials (including further case vignettes, handouts and sample exam questions).

Conclusions - There has been a considerable overall improvement in resources for medical ethics teaching since the time of the last national survey (The Pond Report). ${ }^{1}$ However, provision varies widely from medical school to medical school. The particular needs identified were for full-time teachers, library resources and teaching materials. Wider use of existing organisations concerned with medical ethics could help to meet these needs.

\section{Introduction}

The General Medical Council's recently published report on education places a new obligation on medical schools to include ethics as part of the core curriculum for the training of medical students. ${ }^{2}$ At a conference following publication of the report, however, held at the Royal College of Physicians in

\section{Key words}

Bioethics, education; medical ethics, education; professional ethics, education; resources; medical schools; medical students.
London, concerns were expressed about the resources available to medical schools for teaching in this area. The survey reported here explored thiso issue, looking both at the resources currently availo able to medical schools for ethics teaching and the additional resources they need. The results shows that while most medical schools are able to offe? ethics teaching in one form or another, there are number of well-defined areas in which additionate resources are urgently required.

\section{Method}

A brief (two-page) questionnaire was developed of the basis of the concerns raised at the conference a the Royal College of Physicians and through discus $=$ sion with members of the Association for Healthcares and Medical Ethics Teachers. The draft question naire was piloted with three members of the associac. tion and three deans of medical schools. The finat. version of the questionnaire was then sent to th deans of a list of 28 medical schools in the Unite Kingdom, supplied by the Royal College of. Physicians. A covering letter emphasised the practiô cal focus of the study. A reminder letter was sent to those deans who had not responded after on month. After a further month, those who had stit not responded were telephoned.

The questionnaire focused exclusively on the resources for ethics teaching, as distinct from teaching methods, syllabus time or other aspects of the practical arrangements. The first page covere\& the resources available to respondents, the secon $\mathbb{E}$ the resources they needed, in each of six key areas: personnel, 2) books, journals and other librar resources, 3) video and information technology, 4) teaching materials (for example case vignettes), 5 ग the use of a syllabus, and 6) examination and assess ment. There was also a further more generap question on funding.

Responses in each of the six main sections the questionnaire were scored in arbitrary unitso for resources available, $0=$ none, $1=$ minimas $2=$ adequate, $3=$ ample; and for additional resources. needed, $0=$ none, $1=$ minimal, $2=$ moderate an $3=$ considerable. This gave a maximum overall score 
Figure Resources available and additional resources needed for ethics teaching in $18 \mathrm{UK}$ medical schools

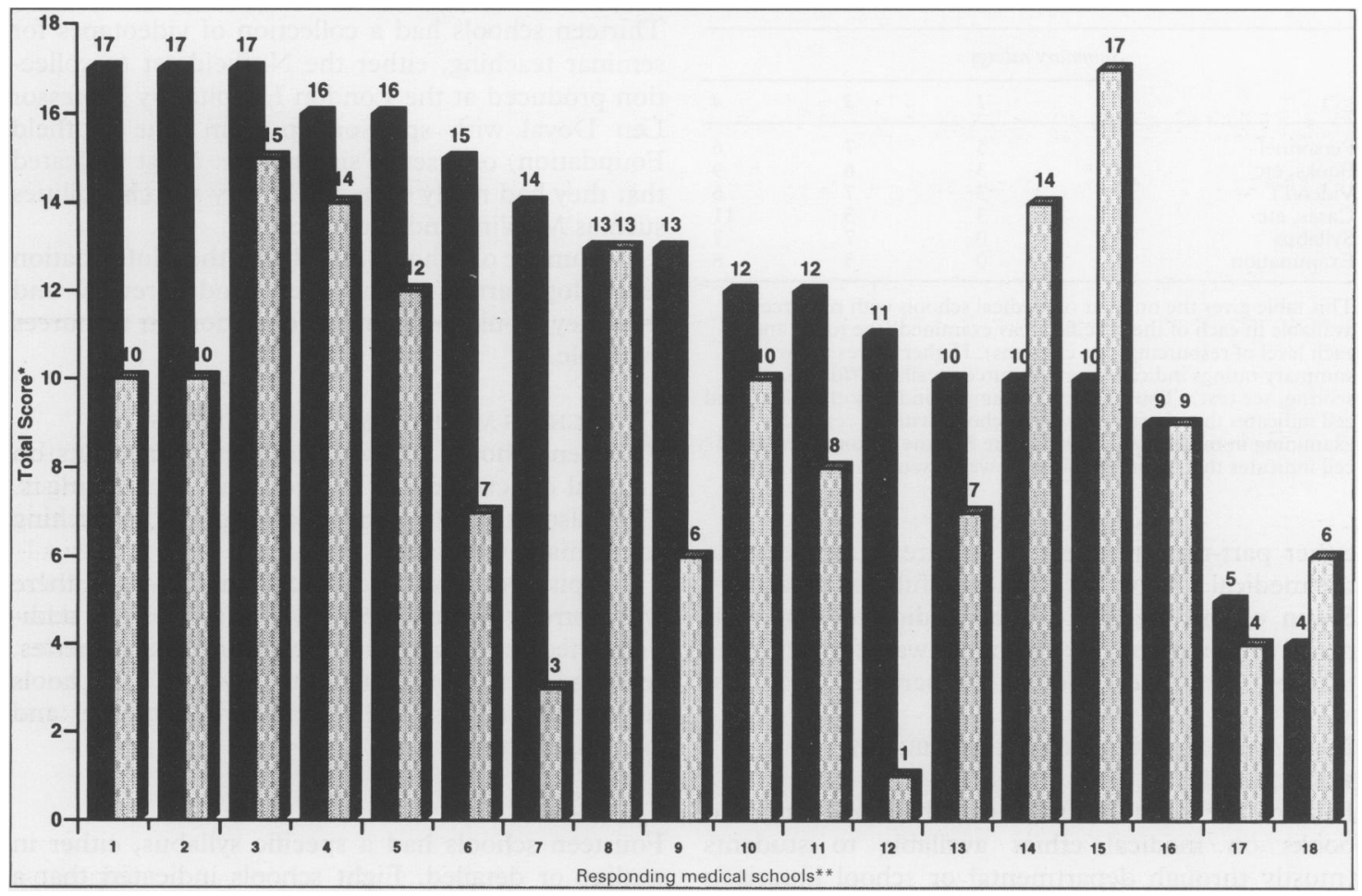

This figure shows the overall levels both of resources available (shaded bars) and of additional resources needed (unshaded bars) for medical ethics teaching in the eighteen medical schools who responded to the questionnaire survey. The responses in six key areas were scored in arbitrary units from 0 to 3, giving a total possible score of 18 both for resources available and for additional resources needed in each medical school (see text for details). Three schools were well resourced (scoring 17), thirteen moderately so (scoring between 9 and 16), and two were under resourced (scoring 4 and 5). A further ten schools were either "unable to comment" or failed to respond.

of 18 for each of resources available and additional resources needed. Further details of the scoring are given in appendix 1.

\section{Results}

Twenty-two replies were received from twenty-eight medical schools, a return rate of $79 \%$. Of the six who did not respond, four were from the ten London schools and only two from the eighteen schools in the rest of the country. A further four schools indicated that they were unable to complete the questionnaire because their curricula were under revision. One respondent taught in two medical schools and replied on behalf of both. There were thus seventeen completed questionnaires covering 18 medical schools.

All those responding indicated that they had resources of some kind for medical ethics teaching. However, the extent and nature of these varied widely. The overall scores for each of the responding medical schools (listed in descending order of resources available) is summarised in the figure. This shows the total resources available (shaded bars) and the total additional resources needed (open bars). As can be seen, while all the responding medical schools had resources of some kind for medical ethics teaching, only three could be said to be really well resourced (scoring 17), while two were poorly resourced in all areas (scoring five and four respectively). Moreover, a majority even of those who were reasonably well resourced, indicated that they still needed considerable additional resources (indicated by the unshaded bars). We return to the interpretation of these results below.

The results for each of the six specific areas (ie excluding funding) are summarised in table 1 (resources available) and table 2 (additional resources needed). The need for additional funding (not shown in the tables) was mentioned by most respondents in relation to one or more of these areas, in particular: a) support for teaching, including full and part-time staff and outside "experts" (such as lawyers and philosophers); b) expansion of library resources; c) development of video and information technology materials, especially for self-tuition; d) development of new teaching materials; and e) research into examination and assessment methods.

Turning now to each of the specific areas, the main findings for resources available and resources needed were:

1) PERSONNEL

Two-thirds of the responding medical schools used 
Table 1 Resources available

\begin{tabular}{llllr}
\hline & \multicolumn{2}{l}{ Summary ratings } & \\
\cline { 2 - 5 } & 0 & 1 & 3 & 4 \\
\hline Personnel & 0 & 5 & 7 & 6 \\
Books, etc & 0 & 3 & 6 & 9 \\
Video/TT & 2 & 3 & 7 & 6 \\
Cases, etc & 1 & 3 & 3 & 11 \\
Syllabus & 4 & 0 & 7 & 7 \\
Examination & 7 & 0 & 3 & 8 \\
\hline
\end{tabular}

This table gives the number of medical schools with resources available in each of the specific areas examined (the rows) and at each level of resourcing (the columns). Higher scores in the summary ratings indicate more resources available (for details of scoring, see text). Thus the 7, for example, in the bottom left-hand cell indicates that there were seven schools with no resources for examining in medical ethics, while the 8 in the bottom right-hand cell indicates that eight schools.were well resourced in this area.

either part-time teachers or lecturers from outside the medical school. Six employed full-time teachers. Seven of the medical schools indicated that their main requirement in this area was for full-time teachers. Four were looking for part-time teachers.

\section{2) BOOKS, JOURNALS AND OTHER LIBRARY RESOURCES}

Half of the schools had more than one hundred books on medical ethics available to students (mostly through departmental or school libraries); most took at least one medical ethics journal and five took five or more. Three schools had databases and many had collections of newspaper clippings, bibliographies and newsletters.

Thirteen of the eighteen schools said that their library resources needed to be updated. The main specific need identified in this area was for books. Eleven schools wanted more books and two suggested that an inter-school loan scheme should be set up. Only two schools wished to take additional medical ethics journals but a further two said they needed additional funding to expand their library resources. Two wanted access to collections of press cuttings.

\section{Table 2 Additional resources needed}

\begin{tabular}{lrrrr}
\hline & \multicolumn{5}{l}{ Summary ratings } \\
\cline { 2 - 5 } & 0 & 1 & 3 & 4 \\
\hline Personnel & 1 & 6 & 4 & 7 \\
Books, etc & 4 & 1 & 11 & 2 \\
Video/IT & 5 & 3 & 9 & 1 \\
Cases, etc & 5 & 1 & 4 & 8 \\
Syllabus & 10 & 0 & 3 & 5 \\
Examination & 9 & 0 & 3 & 6 \\
\hline
\end{tabular}

This table is similar in form to table 1 except that the summary ratings indicate additional resources needed. Higher summary score ratings in this table thus indicate a greater need for additional resources (for details of scoring, see text). Thus in this table the 9, for example, in the bottom left-hand cell indicates that nine schools needed no additional resources for examining in medical ethics, while the 6 in the bottom right-hand cell indicates that six schools needed substantial additional resources in this area.

\section{0) VIDEO/INFORMATION TECHNOLOGY}

Thirteen schools had a collection of videotapes fôf seminar teaching, either the Nuffield set (a colle tion produced at the London Hospital by Professof Len Doyal with sponsorship from The Nuffied Foundation) or a set of similar size. Most indicate? that they had ready access to library search facilitie such as Medline and Bioethicsline.

A number of schools noted that their information technology arrangements were under review and that they would welcome information on resources available.

\section{4) TEACHING MATERIALS/CASE VIGNETTES}

Fourteen schools had well-developed handouts off medical ethics and law in addition to reading listis. They also had collections of long and short teaching cases, many with tutor's notes.

Despite being well-resourced in this area, there was a strong demand from twelve schools for addi tional teaching materials including case vignette reading lists and other handouts. One of the schools suggested setting up a national database and exchange scheme.

\section{5) SYLLABUS}

Fourteen schools had a specific syllabus, either outline or detailed. Eight schools indicated that syllabus (or expanded syllabus) would be usefuis Three said it would be useful to have examples of syllabuses and a further two were planning to write their own.

\section{6) EXAMINATION AND ASSESSMENT}

Eleven of the responding schools included medica ethics in their examinations. Of these, eight used written form of assessment, either a long essay (fou or "unseen" examination (four). Three used OSCES (Objective Structured Clinical Examinations) and one, continuing assessment. Six schools noted the need for sample questions and essay topics for use if examinations.

\section{Discussion}

At the time of the Pond Report, ${ }^{1}$ teaching in medicáp ethics was offered by only a handful of medical schools. A recent review by one of the authors of the report showed that the position has improved to som extent since then, most medical schools now offering teaching in medical ethics, either as a general course or in specific subject areas such as $\mathrm{HIV}^{4}$ and breakin bad news. ${ }^{5}$ The present study, focusing specifically of the question of resources, broadly confirms this positive picture: a majority of medical schoo reported that they have a good supply of books journals, video teaching tapes and case vignette many have, or are developing, a written syllabus; and many include ethical aspects of practice in their exam ination and assessment procedures. 
Although this is encouraging many schools responding to the questionnaire also reported a lack of resources in one or more key areas. It is possible, in addition, that many if not all of those whose only response was that their arrangements were "under review" (four schools), or who failed to respond at all (a further six schools), are under-resourced for medical ethics teaching. There are many reasons for failing to respond to questionnaires and it may be that these schools are in fact well resourced for ethics teaching. But given the practical focus of the questionnaire, its brief format, and our repeated followup, it seems more likely that they failed to respond because they felt that they had, at present, relatively little to offer. If this is right, then, it could be that as many as $50 \%$ of UK medical schools remain inadequately resourced for teaching medical ethics. Moreover, even those who reported that they were relatively well resourced, identified a number of outstanding needs, in particular for additional teaching materials (case vignettes, reading lists, and so forth), access to relevant information technology, sample examination questions, expanded library resources, and full-time teachers.

The overall picture is thus of an improving situation but with some medical schools still seriously under-resourced and a majority requiring additional resources in one or more key areas.

Providing additional resources is partly, and unavoidably, a matter of additional funding. The use of team teaching, piggy-backed on everyday clinical training, can offer a cost-effective and clinically appropriate way of introducing ethical aspects of practice into clinical training. However, medical ethics, like any other academic subject, can only be effectively taught with the active involvement of one or more members of staff carrying direct responsibility for the subject and being actively engaged in research. This is reflected in the survey in the need, expressed by no less than seven schools, for full-time teachers.

Materials for medical ethics teaching are now becoming available both in the $\mathrm{UK}^{6}$ and the USA where the Kennedy Institute of Ethics keeps a collection of course materials from many US medical schools. There are also a number of organisations in the United Kingdom able to offer academic and practical support for the development of ethics teaching, through exchange of information and experience, access to potential teachers, advice on ethics courses and training programmes for course organisers. Besides local university departments, relevant organisations include the Association for Healthcare and Medical Ethics Teachers, the Royal College of Psychiatrists Philosophy Group, and the UK Forum for Teachers of Medical Ethics and Law (see also appendix 2). Wider use of these organisations could help to ensure that this key element in the General Medical Council's core curriculum is speedily and fully implemented in all British medical schools.

\section{Conclusions}

The results of this questionnaire survey indicate that most medical schools are now able to offer teaching in medical ethics, consistent with the requirements of the General Medical Council's new core curriculum. Many schools remain under-resourced in this area, however. The main needs identified were for 1 ) teaching materials, 2) funding for additional library resources, and 3) additional full-time teaching posts. A number of existing academic and professional organisations could contribute to the further development of teaching in this area.

\section{Acknowledgements}

We are grateful to Professor David Morton and other members of the Association for Healthcare and Medical Ethics Teachers for their advice and support, and to all those who responded to the questionnaire survey.

$K W M$ Fulford, DPhil, FRCPsych, is Honorary Consultant Psychiatrist, University of Oxford, and Professor of Philosophy and Mental Health, University of Warwick. Anne Yates, DipEurHum, is General Practice Manager for Dr Neil MacLennan and partners, Oxford, and Tony Hope is Honorary Consultant Psychiatrist and University Lecturer in Practice Skills, University of Oxford. He is also Editorial Associate of the Journal of Medical Ethics. At the time of the study, KWM Fulford was Director, Anne Yates was Project Assistant, and Tony Hope was Project Leader of the Oxford Practice Skills Project, University of Oxford Medical School.

\section{References}

1 Pond D. Report of a working party on the teaching of medical ethics. London: Institute of Medical Ethics Publications Ltd, 1987

2 General Medical Council. Tomorrow's doctors. London: General Medical Council, 1993.

3 Boyd KM. Ethik-Unterricht an medizinischen Hochschulen in GroBbritannien. Zeitschrift fur Miedizinisched Ethik 1994: 40; 93-9.

4 Boyd KM. Implications of HIV infection and AIDS on medical education. Medical Education 1994; 28: 488-491.

5 Boyd KM. Helping future doctors learn how to break bad news. Medical Teacher 1994: 16: 297-301.

6 Hope T, Fulford KWM, Yates A. The Oxford Practice Skills course: ethics, law and communication in health care education. Oxford: The Oxford University Press, 1996.

\section{Appendix 1}

DETAILS OF SCORING FOR SPECIFIC AREAS

Section 1 - Personnel

Resources available: $0=$ none; $1=$ no dedicated personnel (for example, teaching incidental to general clinical training or use of outside lecturers); 2 =part-time only; $3=$ at least one full-time. Additional resources needed: $0=$ none; $1=$ outside lecturers only; 2 =part-time; $3=$ full-time. 
Section 2 - Books, journals and other library resources Resources available: $0=$ none; $1=$ less than 10 books; $2=10-100 ; 3=$ more than 100 . (The number of books was a good indication of overall library resources available). Additional resources needed: $0=$ none; 1 =minimal; $2=$ up-dating of facilities; $3=$ substantial specific needs listed. (Additional library resources needed were generally indicated qualitatively.)

\section{Section 3 - Video/information technology}

Resources available: $0=$ none; $1=$ less than the Nuffield set; $2=$ the Nuffield set or equivalent; $3=$ more than the Nuffield set. (Most schools had access to medline and/or other search facilities). Additional resources needed: $0=$ none; $1=$ minimal; 2 =some extra videos needed; 3 =major gaps in resources.

\section{Section 4 - Teaching materials/case vignettes}

Resources available: $0=$ none; $1=$ minimal; $2=$ intermediate; $3=$ plentiful. Additional resources needed: $0=$ none; $\quad 1=$ minimal; $2=$ general up-dating; $3=$ major gaps in resources. (Responses in this section were mostly qualitative. There was a good correlation between handouts, reading lists and case vignettes.)

\section{Section 5 - Syllabus}

Resources available: $0=$ none; $1=$ time-tabled only; $2=$ outline syllabus; 3 =detailed written syllabus. Additional resources needed: $0=$ none; $1=$ uncertain whether useful; $2=$ possibly useful; $3=$ in preparation or indicated that definitely needed.

\section{Section 6 - Examination and assessment}

Resources available: $0=$ none; $1=$ implicit in clinical assessment; 2 =explicit but no details given; 3 =detailed explicit provision (for example, OSCE and/or written). Additional resources needed: $0=$ none; $1=$ no resources or said to be not appropriate; 2 =needed but no details given; $3=$ detailed specific needs indicated.

\section{Appendix 2}

Editor's Note: The material in this appendix has been collated by the authors of this paper and the fME. Some of $i t$ may be out of date and we apologise for any errors or omissions. The $\mathcal{F M E}$ plans to publish an updated list in a few months' time. If you have any information which you would like included in this list please would you send it either to the authors of this paper or direct to the Editor, FME.

\section{National centres and societies}

The Association of Healthcare and Medical Ethics Teachers, The Medical School, Edgbaston, Birmingham, B15 2TT.
Association for the Study of Medical Educatio $\vec{\nabla}$. (ASME), 2a-4 Perth Road, Dundee DD1 4LN? Scotland.

The British Medical Association, BMA House Tavistock Square, London WC1H 9JP.

The Philosophy and Mental Health Programme Department of Philosophy, University of Warwiclo Coventry, CV4 7AL

Centre for Professional Ethics, University Lancaster, Preston PR1 1TQ.

Centre for Professional Studies, University Central Lancaster, Preston PR1 1TQ

Centre for the Study of Philosophy and Health Care University College of Swansea, Singleton Pare Swansea SA2 8PP.

The Institute of Medical Ethics, Department 95 Medical Postgraduate Education, Academic Centrep Frenchay Hospital, Frenchay Park Road, Bristed BS16 1LE; or Department of Medicine, Royat Infirmary of Edinburgh, Lauriston Place, Edinburgh $\vec{b}$ EH3 9YW.

The Patients Association, 8 Guilford Street, Londoo WC1N 1DT.

The Philosophy Group, The Royal College of Psychiatrists, 17 Belgrave Square, London SW18 8PG.

Society for Applied Philosophy, Belton Hous Grantham, Lincs NG32 2LS.

The UK Forum of Health Care Ethics and Lavi? Faculty of Law, University of Manchester, Oxfor: Road, Manchester M13 9PL.

\section{MA and other courses}

Belfast - Philosophy Department, Queens Collegê University of Belfast, (Marcel Stchedroff, Belfas 245133) - Masters and BA in Applied Ethics. Birmingham - Department of Biomedical Science and Biomedical Ethics, University of Birmingham, The Medical School, Birmingham BT15 2TT 윽 MMedSc (Health Care Ethics) and Post Experience Diploma.

Fife - Centre for Philosophy and Public Affairs University of St Andrews, Fife, Scotland KY16 9AE Dr John Haldane - in service courses on nursing an ethics.

Glasgow - Institute of Law and Ethics in Medicine University of Glasgow, Professor Sheila McLean - Two-year, pare time/one-year, full-time Mphil by research in Philosophy of Medicine; Masters of Nursing wit? some ethics options.

Keele - Department of Philosophy, University of Keele, Staffs ST5 5BG - One-year Postgraduate Diploma in Medical Ethics.

Leeds - Centre for Business and Professional Ethic\& University of Leeds, Leeds LS2 9JT - MA course Health Care Ethics

Liverpool - Department of General Practice, Un versity of Liverpool, PO Box 147, Liverpool L69 3B 
- MSc in Ethics of Health Care; MA in Medical Law and Ethics

London - Centre of Medical Law and Ethics, King's College, University of London, Strand, London WC2R 2LS - Six-month diploma course in Health Care Ethics; MA course in Medical Ethics and Law

London - The Worshipful Society of Apothecaries, Black Friars Lane, London EC4V 6EJ. Dr Don Hill - Diploma in the Philosophy of Medicine.

London - Continuing Education Centre, Imperial College of Science, Technology and Medicine, 558 Sherfield Building, South Kensington, London SW7 $2 \mathrm{AZ}$ - annual 5-day intensive course in medical ethics

Manchester - The Centre for Social Ethics and Policy, University of Manchester, Manchester M13 9PL - MA in Health Care Ethics

Northampton - Nene College of Higher Education,
Broughton Green Road, Northampton NN2 7AL MA in Health Care and Medical Ethics

Sheffield - Centre for Psychotherapeutic Studies, University of Sheffield, 16 Claremont Crescent, Sheffield S10 2TA - MA/Postgraduate Diploma in Psychiatry, Philosophy and Society

Sheffield - Faculty of Law, The University of Sheffield, PO Box 598, Crooksmoor Building, Sheffield S10 1FL - MA/Diploma in Biotechnological Law and Ethics (MABLE)

Swansea - Centre for the Study of Philosophy and Health Care, University College of Swansea, Singleton Park, Swansea SA2 8PP - MA in Philosophy and Health Care

Warwick - Department of Philosophy and School of Postgraduate Medical Edcuation, University of Warwick, Coventry CV4 7AL - Diploma and MA/MSc courses in Philosophy and Ethics of Mental Health

\section{News and notes}

\section{Professor in Palliative Care and Policy}

Irene Higginson has recently joined St Christopher's Hospice as the first ever Professor of Palliative Care and Policy. The post is part of a joint development with King's College London, and Professor Higginson will be heading up the newly established department which will continue to build on St Christopher's national and international reputation of combining research, education and teaching with high quality medical and nursing care.
The new department will develop high quality research-based teaching at a postgraduate level, will evaluate policy and will seek to make palliative care more relevant to people from minority ethnic groups and patients with non-malignant conditions. The work will stress the multidisciplinary nature of palliative care and will have a strong clinical input and relevance. It is aimed at improving the care of patients and their families. 